\title{
Giant liposome micro reactors for controlled production of calcium phosphate crystals
}

Marc MICHEL, Mathias WINTERHALTER , Laurent DARBOIS, Joseph HEMMERLE, Jean Claude VOEGEL, Pierre SCHAAF and Vincent BALL.

Supporting Information.

Supporting Information 1.

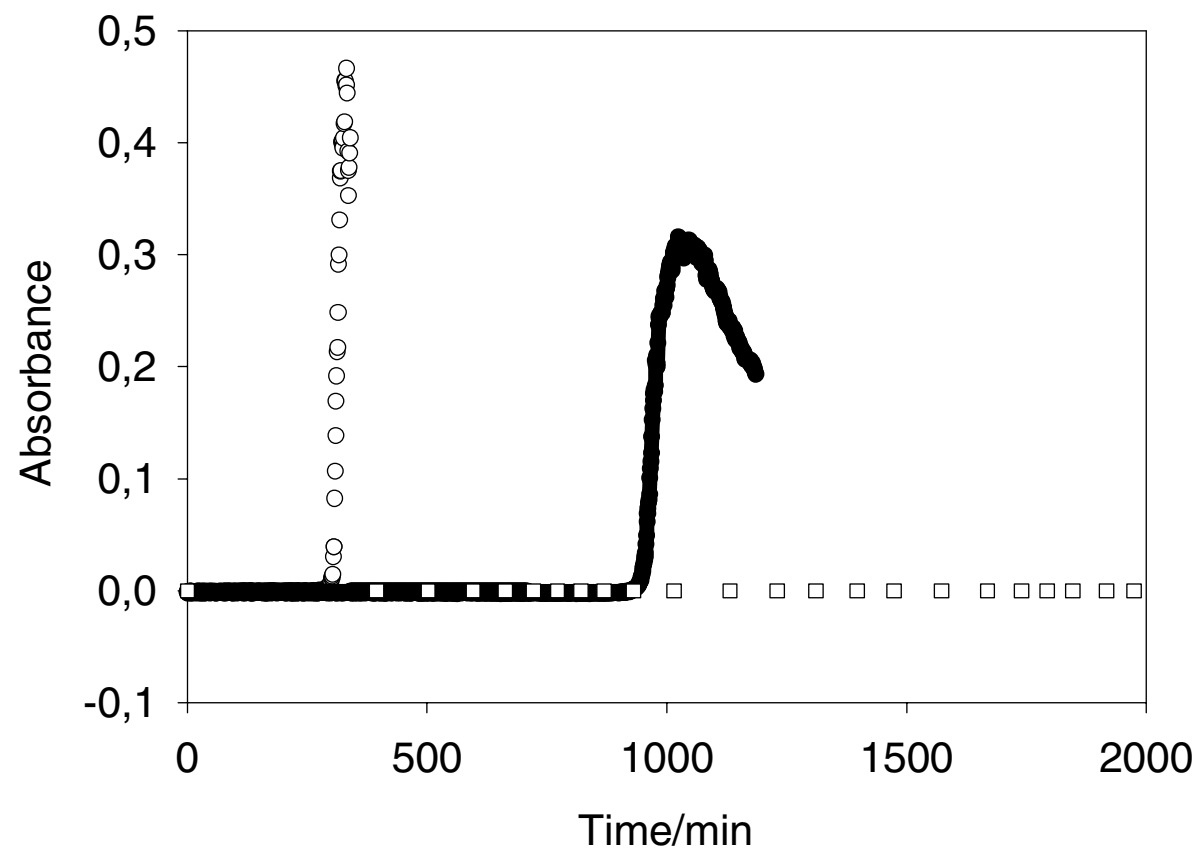

Turbidity measurements at $\lambda=500 \mathrm{~nm}$ of a (○) $6 \mathrm{mM} \mathrm{Ca}^{2+}, 6 \mathrm{mM}$ Phosphate and $10^{-4} \mathrm{M}$ spermine solution, $(\square) 6 \mathrm{mM} \mathrm{Ca}{ }^{2+}, 6 \mathrm{mM}$ Phosphate without spermine and of a (๑) $6 \mathrm{mM}$ $\mathrm{Ca}^{2+}, 6 \mathrm{mM}$ PNP, $10^{-4} \mathrm{M}$ spermine and $0.5 \mathrm{mg} / \mathrm{mL}$ AP solution. Time $\mathrm{t}=0$ corresponds to the addition of spermine in curves $(\bigcirc$, ) and to the addition of spermine and AP in curve $(\mathbf{O})$. The onset of turbidity increase allows to estimate the induction time preceeding the onset of 
phosphate calcium nucleation. In these three experiments, all the components were solubilized in a $10 \mathrm{mM}$. Tris buffer at $\mathrm{pH}=7.4$ containing $0.15 \mathrm{M}$. NaCl.

\section{Supporting Information 2.}

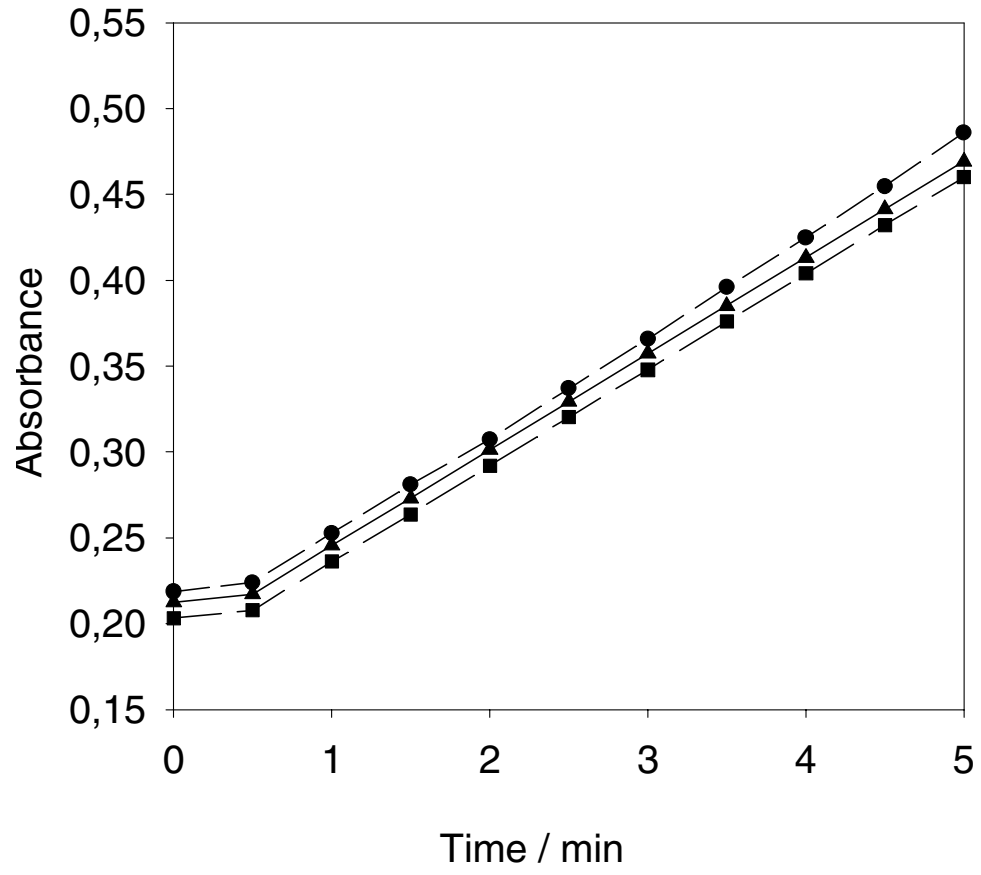

Enzymatic activity of a $0.5 \mathrm{mg} / \mathrm{mL}$ AP solution encapsulated in giant liposomes at differents

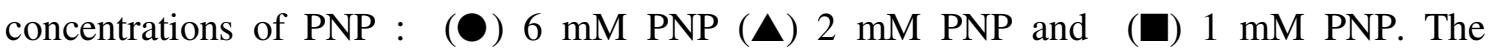
absorbance of the produced paranitrophenol was measured at a wavelength of $405 \mathrm{~nm}$. The absorbance was measured with respect to a reference which was constituted of PNP at the same concentration as in the measurement cuvette. 


\section{Supporting Information 3.}

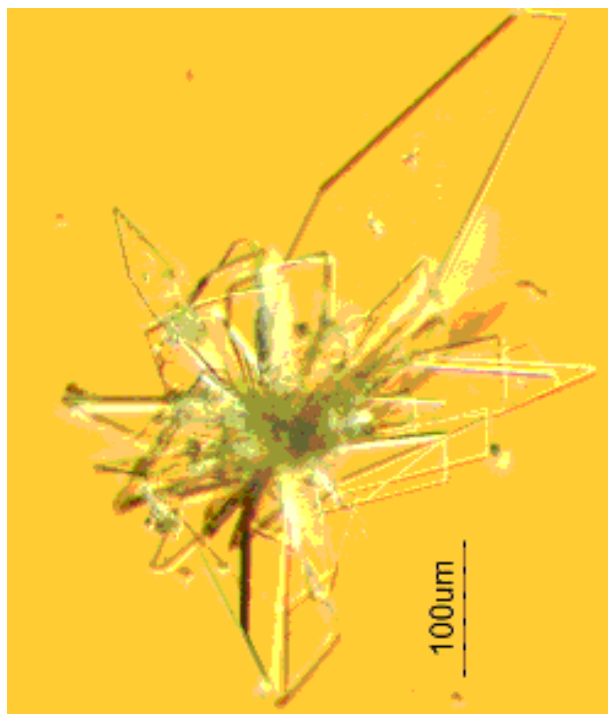

Platelet like particles obtained from a supersaturated calcium phosphate solution $(6 \mathrm{mM}$. in both species) to which spermine was added to a final concentration of $10^{-4} \mathrm{M}$ at time $\mathrm{t}=0$. The particles were observed directly from the Tris- $\mathrm{NaCl}$ buffer containing calcium, phosphate and spermine ions. 